\title{
ELECTRIC FIELD CONTROL OF POLLUTING EMISSIONS FROM A PROPANE FLAME
}

\section{ZAKE ${ }^{1, *}$ \\ I. BARMINA ${ }^{1}$ \\ D. TURLAJS ${ }^{2}$}

Received: 09/11/00

Accepted: 24/09/01
${ }^{1}$ Institute of Physics, University of Latvia Salaspils-1, Miera Street 32, LV-2169, LATVIA

2 Department of Transport and Machinbuilding

Riga Technical University

Riga, Ezermalas Street 6, LV-1014, LATVIA

* to whom all correspondence should be addressed e-mail: mzfi@sal.Iv

\section{ABSTRACT}

The present study is performed with the aim to reduce the levels of polluting emissions from fuel combustion that produce acid rains and the greenhouse effect $\left(\mathrm{NO}_{\mathrm{x}}, \mathrm{CO}_{2}\right)$. The electric field effects on the processes of heat/mass transfer and propane combustion are studied in order to perform electric control of the levels of polluting emissions from the flame. The results of experimental studies show the direct influence of the electric field's enhanced mass transfer on local variations of the flame composition and fuel combustion. The related variations of the flame temperature, processes of soot formation, carbon capture and deposition along the flame channel flow are studied by varying the field strength and the equivalence ratio of the propane-air mixture. The results show that the electric field effect on soot formation, carbon capture and sequestration, for fuel-rich flame flow, can be used to reduce the levels of $\mathrm{CO}_{2}$ emissions from the flame. In addition, the field-enhanced heat/ mass transfer to the channel walls, for fuel-lean conditions, can be used to control the fuel combustion, flame temperature and temperaturesensitive levels of $\mathrm{NO}_{\mathrm{x}}$ emissions. The most pronounced electric field effects on fuel combustion and composition of the products are observed in the limit of the weak fields $\left(\mathrm{U}<1,2 \mathrm{kV}, \mathrm{E}<105 \mathrm{~V} \mathrm{~m}^{-1}\right)$.

KEY WORDS: electric field, heat/mass transfer, fuel combustion, carbon capture and sequestration, $\mathrm{CO}_{2}, \mathrm{NO}_{\mathrm{x}}$ reduction.

\section{INTRODUCTION}

Hydrocarbon fuels (propane, natural gas, and mineral oil) will continue to be the main energy resource for transport and industry in the near future. Combustion of hydrocarbons that results in the formation of polluting emissions $\left(\mathrm{NO}_{x}\right.$, $\left.\mathrm{CO}_{2}, \mathrm{CO}\right)$ can cause harmful effects on the environment and humans. Reduction of the potential risks of human-induced acid rains and global warming requires developing new and effective technologies of combustion control enabling to reduce the levels of the atmospheric emissions. Carbon dioxide is the main greenhouse gas produced by the energy industry. Therefore, effective $\mathrm{CO}_{2}$ reduction is essential for reducing greenhouse effects. Various techniques have been 
developed to perform post combustion control of the levels of $\mathrm{CO}_{2}$ emissions. Safe and reliable technological systems have been developed to capture carbon dioxide and to send it into other destinations, such as deep underground or deep ocean (Holloway, 1996; Brewer et al., 1999). Precombustion decarbonization of fuels with carbon sequestration is the alternative approach to the new energy strategy that allows reducing the emissions of carbon dioxide into the earth's atmosphere (Kaarstad and Audus, 1997). The main idea of this new energy strategy, is to separate the energy function from the carbon content of hydrocarbons and fossil fuels (Socolow, 1997). The starting point of fuel decarbonization is the thermal decomposition of hydrocarbons - a primary fuel is decarbonized and converted into a secondary fuel that has a higher hydrogen-to-carbon ratio. For example, propane can be decarbonized and converted into methane, while the thermal decomposition of methane results in a production of hydrogen that can be burnt to provide clean combustion (Socolow, 1997). It should be noticed that the precombustion thermal decomposition (pyrolysis) of hydrocarbons, is based on carbon capture and sequestration from fuel that significantly reduces the energy to be produced from burning of secondary fuels. For example, during the thermal decarbonization of methane with hydrogen production, only $56 \%$ of the energy content of the methane is extracted, while $44 \%$ stays in the carbon that must be captured and sequestrated from the secondary fuel (Socolow, 1997).

In the combustion processes the thermal decomposition of the hydrocarbons is provoked by the combustion of a portion of the fuel. For fuel-rich conditions the processes of thermal decomposition of the hydrocarbons are followed by soot formation. The rate of soot formation depends on the relative rates of reactions that form soot to those which cause its oxidation. The mechanisms that cause the production of soot in flames are among the most important and unsolved problems of combustion science. For buoyant flames, soot mainly nucleates near the flame sheet, at the outer boundary of the soot production region, while for non-buoyant flames, soot mainly nucleates near the inner boundary of the soot production region (Faeth et al., 1996). Therefore, to obtain the most effective fuel decarbonization and carbon sequestration, the problem reduces to experimental studies of the mechanisms of soot formation that are quite different in buoyant and non-buoyant, laminar or turbulent diffusion flames.

The studies of Place and Weinberg (1965), Mayo and Weinberg (1970) and Weinberg (1981) have shown that carbon particles in the flames are charged and can be manipulated by DC and AC electric fields. These studies demonstrate that electrical control of the processes of heat/mass transfer can be used to control the soot formation and carbon capture from the flame. The investigations presented here are focused on the further development of combustion control techniques using the radial electric field effect on the flame channel flow (Zake et al., 1998; Zake and Purmals, 1999). The field-enhanced variations of the heat/mass transfer and fuel combustion are studied by varying the flame composition and the field strength. More specific, the electric fieldenhanced processes of the heat/mass transfer are studied with the aim to develop an electrical control technique of soot formation, carbon capture and sequestration from the flame that allows reducing the levels of $\mathrm{CO}_{2}$ emissions. In addition, the results of previous investigations have shown (Zake et al., 2000) that the electric field-enhanced processes of the heat/ mass transfer can be used to reduce the levels of $\mathrm{NO}_{\mathrm{x}}$ emissions. Correlation between the field-induced variations of the flame temperature and the levels of $\mathrm{NO}_{\mathrm{x}}$ in the polluting emissions from the water-cooled flame channel flow are presented here.

\section{THEORETICAL BACKGROUND OF THE FIELD EFFECTS ON A FLAME}

Previous investigations illustrate (Place and Weinberg, 1965; Mayo and Weinberg, 1970 and Weinberg, 1981) that application of the electric volume force to the flame flows $(\boldsymbol{F})$ produces fieldforced drift motion of charged compounds (ions, soot particles) in the field direction. The equations for ion flow that take account of diffusion of the charged compounds, convective effects and fieldenhanced drift motion together with Poisson's equation can be expressed as (Smy, 1976):

$$
\begin{aligned}
& \text { v. } \nabla n_{i}+\nabla\left(D_{i} \nabla n_{i}-e \mu_{i} n_{i} E\right)=0 \\
& \nabla^{2} U=e / \varepsilon_{o}\left(n_{i}-n_{e}\right)
\end{aligned}
$$


Here $n_{i}, n_{e}$ are the ion and electron densities in the undisturbed flame flow, $e$ is the electric charge of electrons, $E$ is the electric field intensity, $U$ is the bias voltage of the central electrode, $\mu_{i}$ is the ion mobility,

$$
D_{i}=\mu_{i} \frac{k T}{e},
$$

$k$ the Boltzmann constant,

$T$-temperature of the undisturbed flame flow, $\mathbf{v}$ is the local flow velocity vector, $\varepsilon_{o}$-permittivity of free space.

An approximate expression for the ion density near the biased electrode is given (Smy, 1976) as follows:

$$
\begin{aligned}
& 2 \mu_{i} \frac{k T}{e} \frac{\partial^{2} n_{i}}{\partial r^{2}}-\left(u \frac{\partial n_{i}}{\partial x}+v \frac{\partial n_{i}}{\partial r}\right)= \\
& =\varepsilon_{o} \mu_{i} \frac{\partial}{\partial r}\left(\frac{\partial \Phi}{\partial r} \frac{\partial^{2} \Phi}{\partial r^{2}}+\frac{\partial^{3} \Phi}{\partial r^{3}}\right)
\end{aligned}
$$

$\Phi$ is the potential at any point of the flame, especially $\Phi=U$ on the surface of the electrode, $r$ and $x$ are the radial and axial coordinates of the flame flow.

The first term in equation (3) represents the diffusion of ions, the second term the convection, while the third term represents the fieldenhanced drift of ions. In the limit of a weak field, the third term in equation (3) can be neglected and the ion current to the biased surface is determined by diffusion and convection effects. In the limit of a strong field and thick sheath, the first term in equation (3) can be neglected and the ion transfer to the biased electrode is a result of the convective flow rate and the radial drift velocity. In this limit, the sheath-convection of ions effectively determines the ion current that can be varied by varying the relation between the electric and inertial forces acting upon the flame. For strong fields, all ions convected into the sheath are driven by the field to the electrode and the ion current $\left(I_{i}\right)$ can be approximated by the relation $I_{i} \approx U^{n}$, where $n \approx 0.5-0.8$. If the ion density decreases and the sheath expands, the average electric field in the expanding sheath decreases and only part of the ions convected into the sheath suffers electrically induced variations of their convective velocity, while most of the ions are driven out and do not reach the electrode. In this limit the ion current can be approximated by the linear voltage dependence $I_{i} \approx U$.

In fact, the elastic collisions between ions and gaseous compounds (fuel compounds and hydrocarbon radicals) result in an effective momentum transfer from ions to neutrals. The momentum transfer produces the field-enhanced variations of the velocity vectors for neutrals $\left(\mathbf{v}_{\alpha}\right)$ (Zake and Purmals, 1999) and generates the additional mass flow of neutrals $\mathbf{j}_{\alpha}$ :

$\mathbf{j}_{\alpha}=\rho_{\alpha}\left(\mathbf{v}_{\alpha}-\mathbf{v}_{o}\right) \approx\left(M_{i} / e\right) \mathbf{j}_{i}$,

where $\rho_{\alpha}, \mathbf{v}_{\alpha}$ are the mass concentration and velocity of the component, $\mathbf{v}_{\mathrm{o}}$ is the mass average velocity of an undisturbed flame flow, $M_{i}$ is the mass of ions, $\mathbf{j}_{i}$ is the density of ion current.

Consequently, the convective and sheath effects that determine the electric field-enhanced ion flow in a flame have important implications on the field-enhanced variations of the local mass fraction of fuel compounds $\left(W_{j}\right)$ in the vicinity of the biased electrode and can be expressed as:

$W_{j}=\rho_{\alpha}=-\nabla j_{\alpha}+\frac{M_{i}}{e} j_{i}$

Thus, due to the field-enhanced mass transfer of hydrocarbons, the local concentrations of fuel compounds can become richer or leaner. Moreover, the local variations in the mass concentration of hydrocarbons $\left(\rho_{\alpha}\right)$ can produce variations of the Arrhenius-like fuel mass consumption rate $W_{\alpha}$ :

$W_{\alpha}=-\dot{\rho_{\alpha}}=k_{o}\left[c_{\alpha}\right]^{\beta}\left[c_{o x}\right]^{\gamma} e^{E_{\alpha} / \mathrm{RT}}$

Here $c_{\alpha}, c_{o x}$ are the local mass fractions of the fuel compounds and oxygen, $\beta, \gamma$ are the rate parameters, $k_{o}$ is the pre-exponential factor, $E_{\alpha}$ is the activation energy, $R$ is the universal gas constant. For fuel-lean conditions $W_{j}<W_{a}$, and the electric field-enhanced radial mass transfer of neutrals produces the local increase in the rate of fuel combustion and the enthalpy produced by the reactions in the vicinity of the biased electrode. As a result, a local increase in the temperature can be obtained. For fuel-rich conditions $W_{j}>W_{a}$, and the field-enhanced mass transfer of hydrocarbons gives rise in the local mass fraction of fuel compounds (hydrocarbon radicals and radical ions). The reaction rate for such conditions is weakened while the local rate of soot formation increases. In fact, the dominant variations in the flame compo- 


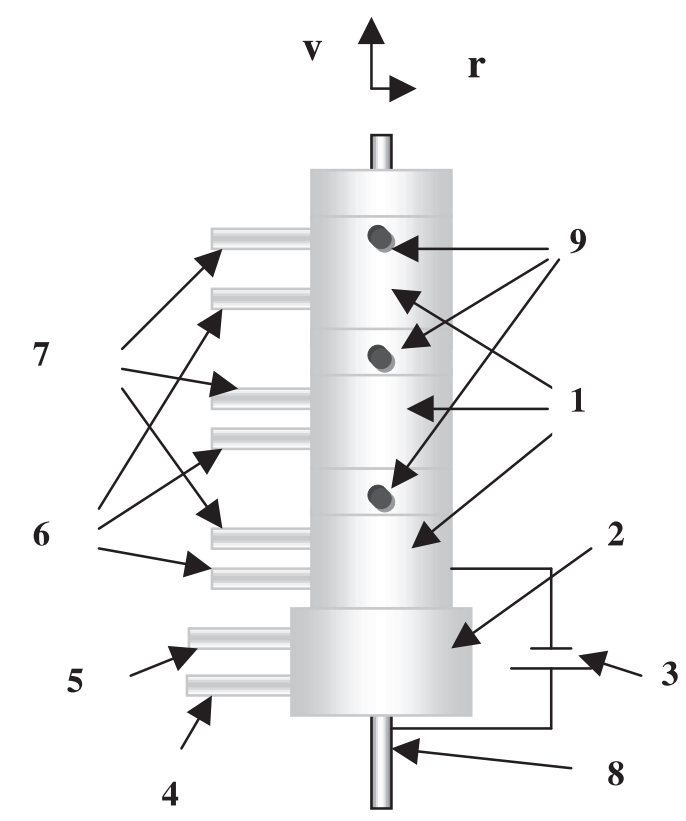

Figure 1. Schematic of the water cooled channel: 1-water-cooled sections of the channel, 2-burner, 3-DC power supply, 4-air supply, 5-propane supply, 6-water inlets, 7-water outlets, 8-central electrode, 9-peepholes for the diagnostic tools.

sition develop in the vicinity of the negatively biased electrode, since the density of positive ions in the flame significantly exceeds the density of negative ions and their contribution to the fieldenhanced mass transfer tends to be negligible.

\section{EXPERIMENTAL PROCEDURES}

The present experimental studies of the radial electric field effect on the processes of heat and mass transfer are focused on in-flame measurements of temperature and composition. Calorimetric measurements of the cooling water flow are also performed. These studies are based on a test facility developed previously (Zake et al., 2000). The investigation of the electric field effects on the flame sooting, carbon capture and sequestration is carried out along the pyrolysis zone of propane-air flame using a sectioned water-cooled channel with length of $250 \mathrm{~mm}$ and with $40 \mathrm{~mm}$ inner diameter. The length of the first and second sections of the cylindrical channel was $50 \mathrm{~mm}$, while the length of the third section was $75 \mathrm{~mm}$. The diagnostic sections are located between the water-cooled sections and have peepholes with a diameter of $5 \mathrm{~mm}$, which allow inserting the diagnostic tools (thermocouples, gas sampling probes) into the flame. The upstream part of the flame flow from the watercooled channel enters into the quartz tube of length $500 \mathrm{~mm}$, which promotes progression of the fuel combustion along the tube. The radial DC electric field is applied to the flame flow in a space between the supporting channel walls and positively or negatively biased central electrode with a diameter of $5 \mathrm{~mm}$ that is aligned along the channel up to a distance of $250 \mathrm{~mm}$ from the exit of the burner. Figure 1 shows a schematic of the experimental setup.

The radial and axial temperature distributions within the flame flow are measured using thermocouples $(\mathrm{Pt} / \mathrm{Pt}-\mathrm{Rh})$, which are inserted through the peepholes (Figure 1) and moved across the flame with an accuracy of $0.5 \mathrm{~mm}$. To obtain the axial and radial distributions of the flame composition and relative mass fractions of the flame compounds, the local gaseous samples are extracted from the flame flow by using microprobe technique, and then analysed by absorption spectroscopy in the range of $2-15 \mu \mathrm{m}$ using an absorption infrared spectrometer (Specord-IR). A portable gas-analyzer (Testo 33R) is used to study the composition of emissions (CO, ppm; $\left.\mathrm{CO}_{2}, \% ; \mathrm{NO}_{\mathrm{x}}, \mathrm{ppm}\right)$, the equivalence ratio of propane air mixture $(\alpha)$ and the flame temperature at the outlet of the water-cooled channel, as well as at the outlet of the quartz tube.

The electric field effect on the heat/mass transfer processes in the flame channel flows was estimated from the local field-enhanced variations of the flame temperature, composition and heat loss from the flame. The electric field effect on the heat transfer to the water-cooled channel walls is estimated from the calorimetric measurements of the cooling water flow for each section. The electric field effect on soot formation and carbon capture on the surface of the central electrode was estimated from the measurements of the weight (m) of the deposited soot particles. The electric field effect on fuel decarbonization and carbon sequestration was estimated from the radial and axial measurements of the intensity of the band absorption (I) of hydrocarbons $\left(\mathrm{CH}_{4}, \mathrm{C}_{2} \mathrm{H}_{2}\right), \mathrm{CO}_{2}$ and $\mathrm{CO}$ and from the variations of the levels of $\mathrm{CO}_{2}$ and $\mathrm{CO}$ at the outlet of the quartz tube.

The air injection rate varied within a range of 5-35 liters minute ${ }^{-1}$ with an accuracy of 0.5 liters 
minute ${ }^{-1}$. The propane flow rate varied from 1 to 3 liters minute ${ }^{-1}$ with an accuracy of 0.1 liters minute $^{-1}$. These conditions corresponded to the overall equivalence ratio of propane-air mixture $(\alpha)$ ranging from 0.3 to 1.5 . It should be noted that the fuel and air are introduced separately along the burner channel where mixing takes place. Therefore, regions with a local equivalence ratio can exist within the flame channel flow, which is either richer or leaner than the overall equivalence ratio. The inlet velocity of laminar propaneair mixture varies from 0.2 to $0.5 \mathrm{~m} \mathrm{~s}^{-1}$ with the Reynolds number varying from 500 to 1300 .

The radial field effect on the flame is studied by varying a bias voltage of the central electrode. The bias voltage of the central electrode is varied within the range of $-3 \mathrm{kV}-+3 \mathrm{kV}$, while the ion current to the collecting electrode is limited to $3 \times 10^{-4} \mathrm{~A}$.

\section{RESULTS AND DISCUSSION \\ Electric field effect on the heat/ mass transfer and fuel combustion}

Experimental studies have been conducted in order to explore the basic mechanisms by which the radial electric field produces variations in the processes of heat/ mass transfer and fuel combustion and may allow electric control of the levels of polluting emissions.

The previous investigations in the free flame flow by Zake et al. (1998) clearly show that, under conditions of positively biased central electrode, the radial electric field enhances the sheath-convection of positive ions $\left(\mathrm{C}_{2} \mathrm{H}_{4}^{+}, \mathrm{C}_{3} \mathrm{H}_{3}^{+}, \mathrm{CHO}^{+}\right.$, etc. $)$and hydrocarbon radicals from the reaction zone of the flame outward. Depending on the ion density, flow rate and field strength, the field-enhanced sheathconvection of fuel compounds reduces the rate of fuel combustion (equation 6) and heat release in the central part of the flame, while enhances the outer diffusion flame formation. The investigations of the electric field effects on the formation of $\mathrm{NO}_{\mathrm{x}}$ emissions have shown that the field-enhanced quenching of the reaction zone and destruction of $\mathrm{NO}_{\mathrm{x}}$ in corona discharge can be used to reduce the levels of $\mathrm{NO}_{\mathrm{x}}$ emissions from the district heating boiler houses (Zake et al., 2000).

The present investigations of the electric field effects on the formation of polluting emissions are performed along the sectioned water-cooled channel both for negatively and positively biased central electrode that allows to vary the direction of

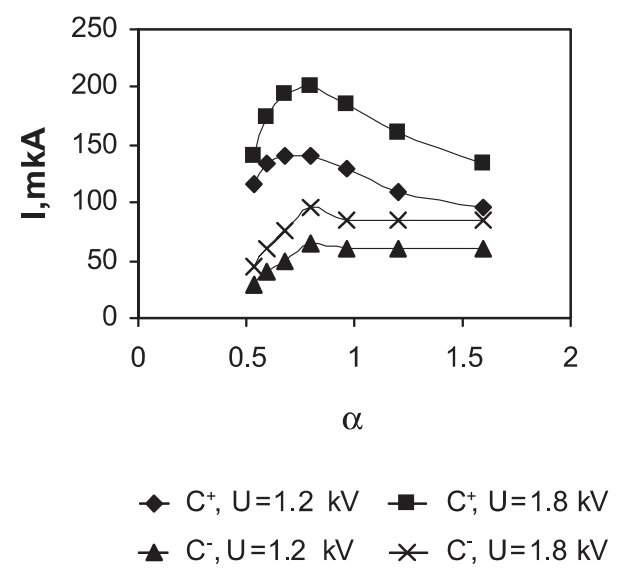

Figure 2. Influence of equivalence ratio $(\alpha)$ and bias polarity on the ion current

the field-enhanced radial mass transfer of the hydrocarbons across the flame. In fact, for conditions of positive bias of the central electrode $\left(\mathrm{C}^{+}\right)$, the dominant mass transfer of the hydrocarbons is directed from the flame core to the negatively biased water-cooled channel walls. The ion-saturation for such conditions fails to occur, and the voltage dependence of the sheath-convection current of hydrocarbon ions that is collected by the channel walls, can be approximated as $I_{i} \approx U^{n}$, where $n \approx 0.8$-1 (Zake et al., 2000). For the negatively biased central electrode $\left(\mathrm{C}^{-}\right)$the dominant mass flux of the hydrocarbons is directed into the flame core. The current slightly reduces and the linear voltage dependence of the ion current is observed up to the sheath breakdown $(\mathrm{U}>2 \mathrm{kV}): I_{i} \approx e n_{i} U$. The linear voltage dependence of the ion current indicates that the average electric field in the expanding sheath decreases by increasing the bias voltage, and a part of the ions that are convected into the sheath then are convected along the flame channel flow and do not reach the electrode.

The field-enhanced ion sheath convection is strongly influenced by the equivalence ratio of the propane-air mixture burner exit flow, determining the intensity of fuel combustion along the flame channel flow, flame temperature, density of charged particles (hydrocarbon ions) and the flame stretch rate along the water-cooled channel. Increasing the equivalence ratio of propaneair mixture, the ion current tends to increase, and the maximum value of the ion current is reached at $\alpha \approx 0.8-1$ (Figure 2). 


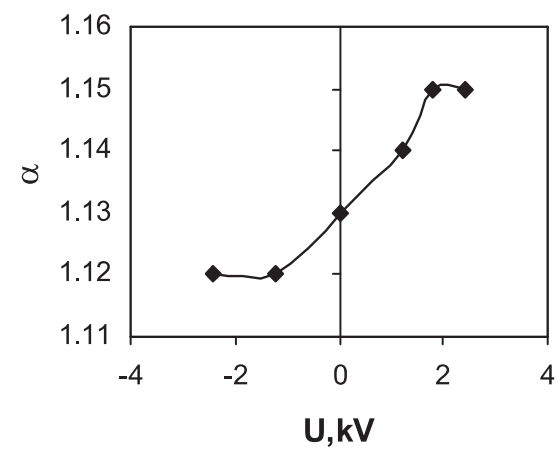

(a)

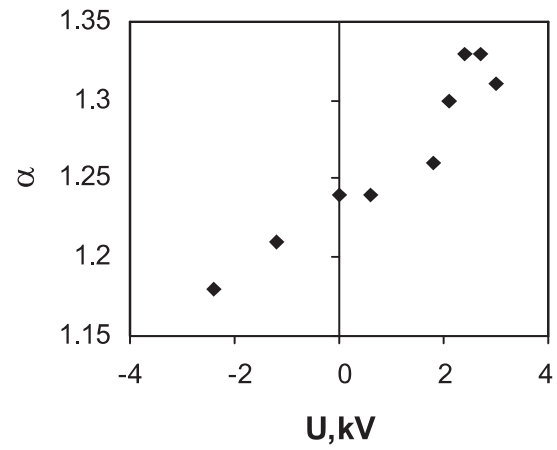

(b)

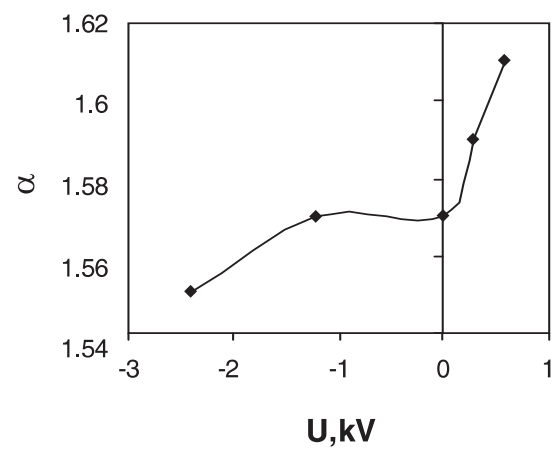

(c)

Figure 3. The electric field effect on the equivalence ratio of the flame flow at the outlet of the water-cooled channel by varying the equivalence ratio of the undisturbed burner exit flow $(\mathrm{U}=0)$ and bias polarity of the central electrode. a) $\alpha(U=0)=1.13$; b) $\alpha(U=0)$ $=1.24$; $) \alpha(U=0)=1.57$
With a further increase of $\alpha$, the field-enhanced ion transfer reduces and this in turn reduces the field effect on the heat/mass transfer and fuel combustion. The field enhanced sheath-convection of the ions and the field-enhanced mass transfer of the hydrocarbons disturb the mass fraction profiles along the pyrolysis zone of the channel flow and cause local variations of the equivalence ratio and flame temperature. Consequently, for fuel-lean burner exit flow $(\alpha>1)$ and positive bias $\left(\mathrm{C}^{+}\right)$the field enhances mass transfer of the hydrocarbons from the flame core outwards. In such a case the reactant concentration at the channel walls becomes more stoichiometric, thus enhancing fuel combustion in the near vicinity of the channel surface, where $\mathrm{W}_{\mathrm{j}}<\mathrm{W}_{\alpha}$. Along the flame core $(\mathrm{R}<10 \mathrm{~mm})$ the reactant concentration becomes less stoichiometric, the equivalence ratio of propane-air mixture increases and the reaction intensity is weakened. As the fuel combustion develops closer to the water-cooled surface, the amount of heat (q) that is transferred to the water-cooled channel walls increases. Therefore, the flame temperature loss increases and the temperature of the reaction zone decreases.

The reverse field effect on the local equivalence ratio and flame structure is observed for the case of negative bias voltage $\left(\mathrm{C}^{-}\right)$. For such conditions the mass transfer of the hydrocarbons promotes more intense fuel combustion into the flame core, while reduces the rate of fuel combustion and heat release in the vicinity of the water-cooled channel walls. Recent studies clearly show that the fieldenhanced local variations in the equivalence ratio of propane-air mixture, flame temperature and fuel combustion, that are initiated in the pyrolysis zone of the channel flow, develop along the flame core. Thus, the equivalence ratio at the outlet of the water-cooled channel tends to increase for $\mathrm{C}^{+}$, while it decreases for $\mathrm{C}^{-}$(Figure 3 ).

For the fuel-lean conditions, the temperature at the exit of the water-cooled channel decreases as the air excess along the flame core is increased $\left(\mathrm{C}^{+}\right)$, while the temperature tends to increase as the air excess decreases $\left(\mathrm{C}^{-}\right)$and the fuel combustion along the flame core approaches the stoichiometric conditions $(\alpha \rightarrow 1)$ (Figure 4).

The phenomenon is quite adverse for a fuel-rich burner exit flow $(\alpha<1)$. For the case of the negative bias voltage $\left(\mathrm{C}^{-}\right)$the radial electric field 


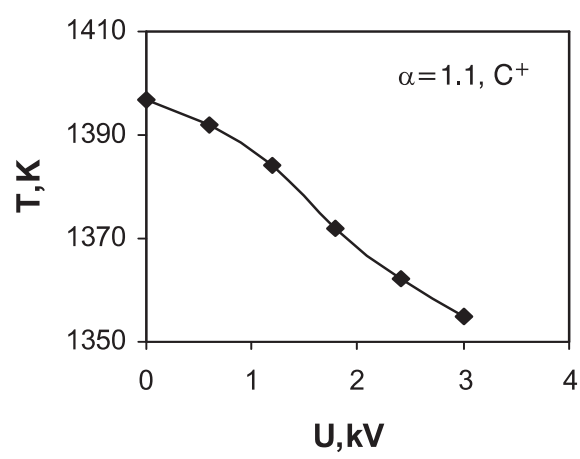

(a)

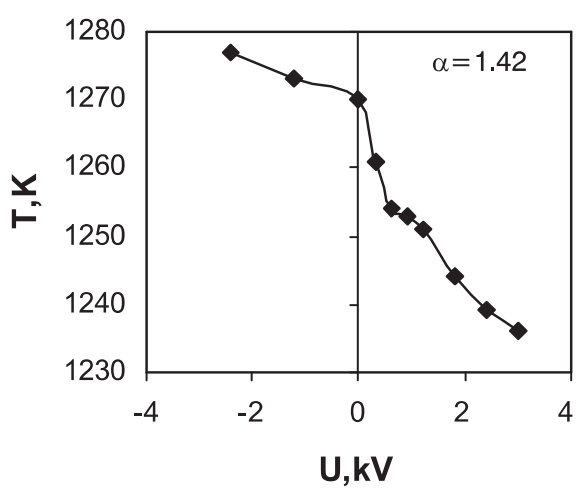

(b)

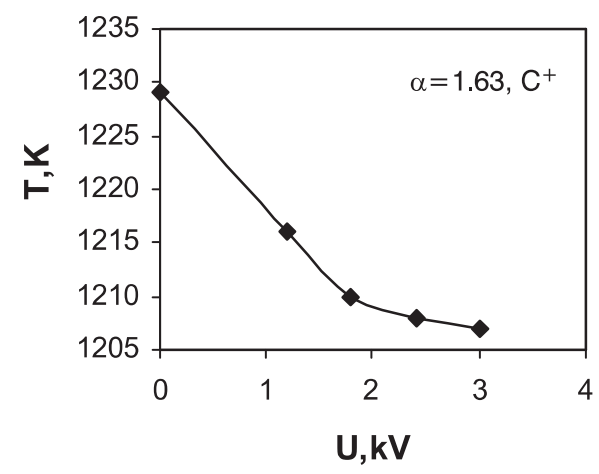

(c)

Figure 4. Electric field effect on the temperature of the products at the outlet of the watercooled channel

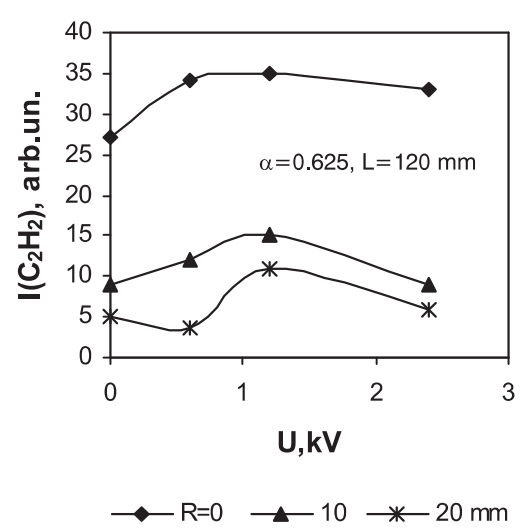

Figure 5. The electric field-enhanced local variations of the intensity of $\mathrm{C}_{2} \mathrm{H}_{2}$ absorption $(v=729$ $\mathrm{cm}^{-1}$ ) for fuel-rich conditions and negatively biased central electrode.

enhances the mass transfer of the hydrocarbons into the flame core. As a result of the fieldenhanced mass transfer, the mass fraction and absorption of hydrocarbons increases in the vicinity of the central electrode $(\mathrm{R}=0)$, while it slightly decrease in the outside part of the flame core. Note that the dominant increase in the local mass fraction and absorption of hydrocarbons $\left(\mathrm{C}_{2} \mathrm{H}_{2}\right.$, $\left.\mathrm{CH}_{4}\right)$ is observed in the vicinity of the central electrode $(\mathrm{R}=0)$ and $\mathrm{U}<1.2 \mathrm{kV}$ (Figure 5).

For such conditions the mass fraction of the hydrocarbons along the flame core becomes less stoichiometric and the equivalence ratio reduces by reducing their mass consumption rate $\left(W_{j}>W_{a}\right)$. Therefore, the combustion intensity in the flame core is weakened and the temperature along the flame core reduces as well, while the temperature at the channel walls slightly increases (Figure 6). The dominant field effect on the flame temperature is observed at $\alpha>0.6$ and it decreases by reducing the equivalence ratio of the burner exit flow $(\alpha<0.6)$ and ion sheath convection current (Figures 2 and 6).

As mentioned previously, the electric field-forced mass transfer and the local variations of the flame composition and fuel combustion show a direct influence on the heat transfer along the channel walls. Depending on the equivalence ratio of the burner exit flow $(\alpha)$, bias voltage and the polarity of the central electrode, the total heat loss from the flame can be increased or reduced, as shown in Figures $7 \mathrm{a}$ and $\mathrm{b}$. The results show that the 

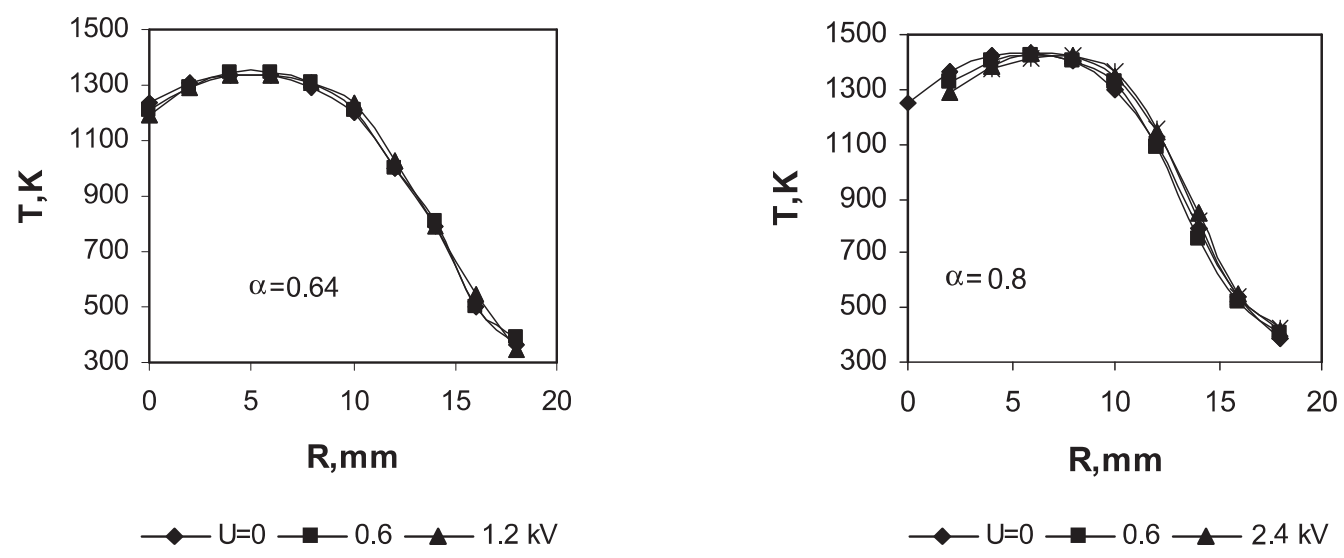

Figure 6. The effect of the equivalence ratio on the electric field-induced variations of the flame temperature profiles in the water-cooled channel $(\mathrm{L}=120 \mathrm{~mm})$

most effective field-enhanced heat transfer to the channel walls and most effective heat loss from the flame can be reached for the positive bias $\left(\mathrm{C}^{+}\right)$and for the conditions of the stoichiometric or fuel-lean mixture $(\alpha \geq 1)$. In contrast, the field enhanced reduction of the heat transfer to the channel walls with subsequent reduction of the heat loss from the flame, can be achieved for negative bias $\left(\mathrm{C}^{-}\right)$and fuel-rich conditions $(\alpha<1)$ (Figures 7 and 8).

The voltage dependence of the field-enhanced heat loss along the flame propagation shows that the dominant variations of the field-enhanced heat loss from the flame can be reached along the pyrolysis zone of the flame. Hence, for the stoichiometric and fuel-lean conditions $(\alpha \geq 1)$, the most important field-enhanced variations of heat/ mass transfer and fuel combustion are observed at the initial stage of the channel flow formationalong the first section of the water-cooled channel (Figures 8a and b). For fuel-rich conditions $(\alpha<1)$, the pyrolysis zone of the flame flow extends along the water-cooled channel and, in this limit, the field-enhanced variations of the heat/mass transfer and fuel combustion develop up to the outlet of the water-cooled channel (Figures $8 \mathrm{c}$ and $\mathrm{d}$ ).

It should be noted that the propane combustion for fuel-rich conditions leads to an intense soot formation and deposition on the central electrode. Such kind of carbon capture from the zone of reaction reduces the total amount of carbon that is burned along the flame channel flow and reduces the heat amount that is produced by the propane combustion. Moreover, as a result of carbon capture and sequestration, the flame temperature and total heat loss from the flame decrease as it shown in Figures $8 \mathrm{c}$ and d.

\section{Electric control of carbon capture and fuel decarbonization}

Previous investigations (Frenklach, 1996; Kennedy, 1997) have shown that soot formation for fuel-rich conditions begins with fuel pyrolysis and homogeneous nucleation of the soot precursors in the gas phase. The nucleation of precursors is followed by coalescence of the condensed compounds and particle growth with aggregation and surface deposition.

After simulation of the processes of soot formation and calculation of the concentrations of soot precursors, the generation of soot is assumed through the dominant reactions (Chomiak et al., 1996):

$\mathrm{CH}_{4} \rightarrow 2 \mathrm{H}_{2}+\mathrm{C}$

$\mathrm{C}_{2} \mathrm{H}_{2} \rightarrow \mathrm{H}_{2}+2 \mathrm{C}$

Therefore, acetylene and methane are defined as soot precursors that initiate soot formation. It is observed that acetylene initiates fast polymerization reactions by varying the carbon/ hydrogen content in the aromatic rings (Glassman, 1989; Malcev et al., 1977):

$$
\mathrm{C}_{\mathrm{n}} \mathrm{H}_{\mathrm{m}}+\mathrm{H} \rightarrow \mathrm{C}_{\mathrm{n}} \mathrm{H}_{\mathrm{m}-1}+\mathrm{H}_{2}
$$




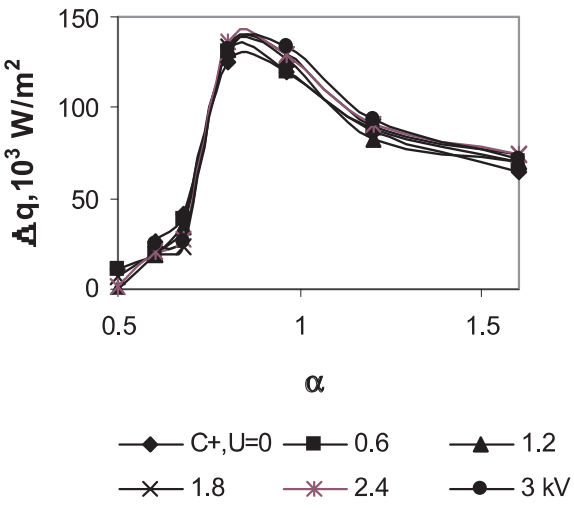

(a)

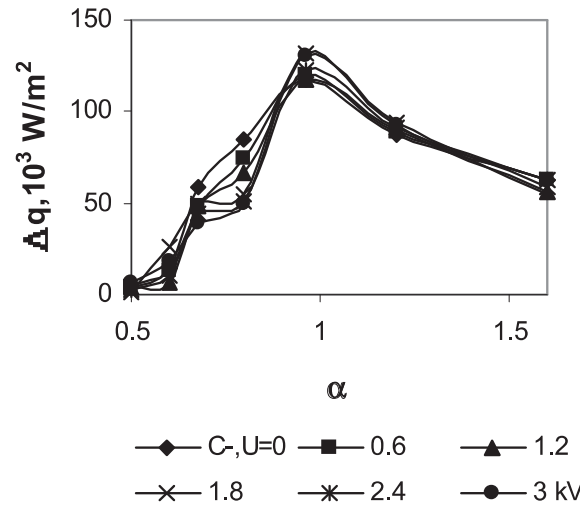

(b)

Figure 7. Effect of the equivalence ratio $(\alpha)$ and bias voltage of the central electrode on the field-enhanced total heat flux to the channel walls: (a) positive bias $\left(\mathrm{C}^{+}\right),(\mathrm{b})$ negative bias $\left(\mathrm{C}^{-}\right)$.

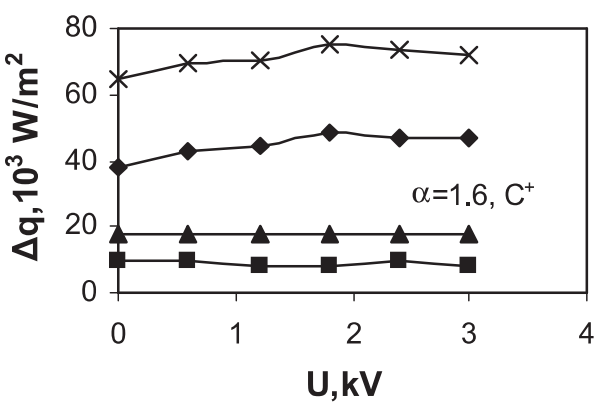

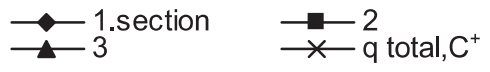

(a)

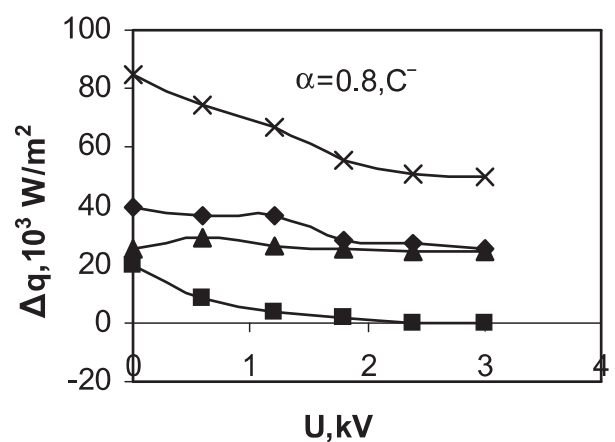

$\underset{\sim-3}{\longrightarrow \text { section } \quad \longrightarrow \text { q total }}$

(c)
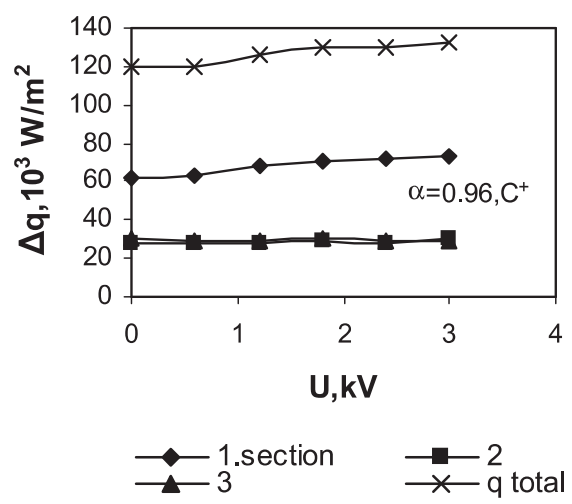

(b)
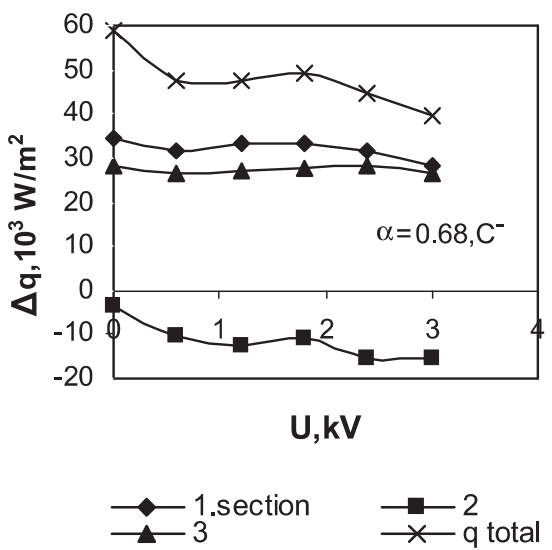

(d)

Figure 8. Effect of the equivalence ratio and polarity of the central electrode on voltage dependence of the electric field-enhanced heat loss from the flame. 

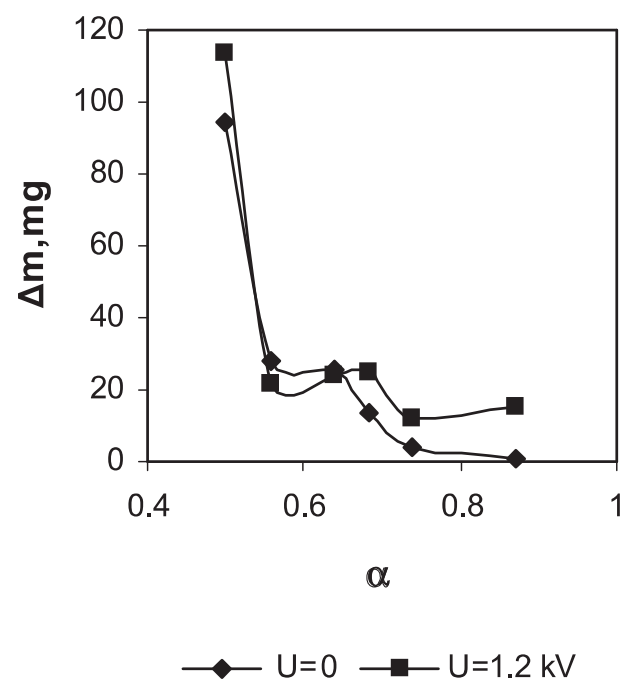

Figure 9. The influence of $\alpha$ on soot formation and deposition on the electrode

In fact, due to the high activation energy of the reactions (equations 7,8 ), the soot formation paths are blocked, if the flame temperature is lower than the threshold temperature $(\mathrm{T} \approx 1300 \mathrm{~K})$ (Glassman, 1989), above which intense soot formation in the fuel-rich flame can occur. In addition, a critical mass fraction of the soot precursors is needed to initiate the process of soot formation. Investigations of the soot formation and deposition on the central electrode along the undisturbed $(\mathrm{U}=0)$ pyrolysis zone of the watercooled flame channel flows, confirm that the most intensive soot formation and deposition on the central electrode develop above T>1300-1400 K and at $\alpha<0.8$ (Figure 9).

For fuel-rich conditions $(\alpha<0.8)$, the threshold temperature of soot formation is achieved in the outer part of the flame core (at $\mathrm{R} \approx 5-10 \mathrm{~mm}$ ) and at a distance of $L \approx 80-100 \mathrm{~mm}$ from the outlet of the burner. The results show (Figure 3), that the field-enhanced mass transfer of the hydrocarbons from the outside part of the flame core to the central electrode that is observed for the negative bias voltage $\left(\mathrm{C}^{-}\right)$, reduces the equivalence ratio of propane-air mixture. The reduction of the equivalence ratio initiates a more intensive soot formation in the flame core and enhances soot deposition along the surface of the central electrode (Figure 9). The strongest field effect on soot formation and deposition is observed at $\alpha>0.6$. By reducing the equivalence ratio of the fuel-rich flame flow $(\alpha<0.6)$, the field effect on soot formation and deposition (Figure 9) decreases. The reason for this is a decrease of the ion sheath convection current with subsequent field-enhanced decrease of the hydrocarbon mass transfer that is observed under fuel-rich conditions (Figure 2b). By increasing the negative bias voltage of the central electrode, the field-enhanced soot formation and mass growth of the deposited soot particles increase up to a maximum value that is obtained at $U=1.2 \mathrm{kV}$. In the limit of strong fields (U>1.2 $\mathrm{kV}$ ), the total mass of the deposited soot particles reduces and approaches a constant value as it is shown in Figure 10.

The competitive field effects on the mass transfer and fuel combustion influence the shape of the voltage dependence of the mass growth of deposited soot particles (Figure 10). Figures 5 and 6 illustrate that the field-enhanced increase in the absorption and mass fraction of the soot precursors $\left(\mathrm{C}_{2} \mathrm{H}_{2}\right)$, along the flame core correlates with the temperature reduction and the temperature reduces below the threshold temperature. Therefore, soot formation paths (equations 7 and 8) are blocked and the radial electric field confines the process of soot formation and deposition on the electrode. In addition, by increasing the negative bias voltage above $1.2 \mathrm{kV}$ a radial sheath expansion is observed. This sheath expansion reduces the field strength along the flame core and that in turn reduces the field-enhanced radial mass transfer of soot precursors to the electrode (Figure 5). For such conditions the rate of soot formation is reduced, and the process of soot formation is found extending along the flame core. Consequently, at $\mathrm{U}>1.2 \mathrm{kV}$ a more uniform mass growth of the deposited soot particles along the electrode can be obtained. The deposited elemental carbon can be sequestered and used as carbon black for different practical applications. As a consequence of fuel combustion under the fuel-rich conditions, the mass transfer of soot particles to the negatively biased electrode and carbon capture from the flame, decreases the levels of $\mathrm{CO}_{2}$ emissions in the products, by reducing the intensity of the infrared band absorption of $\mathrm{CO}_{2}$ $\left(v=2349 \mathrm{~cm}^{-1}\right)$. The correlation between the mass growth of the deposited soot particles and absorption of $\mathrm{CO}_{2}$ in the products is illustrated in Figure 11. 


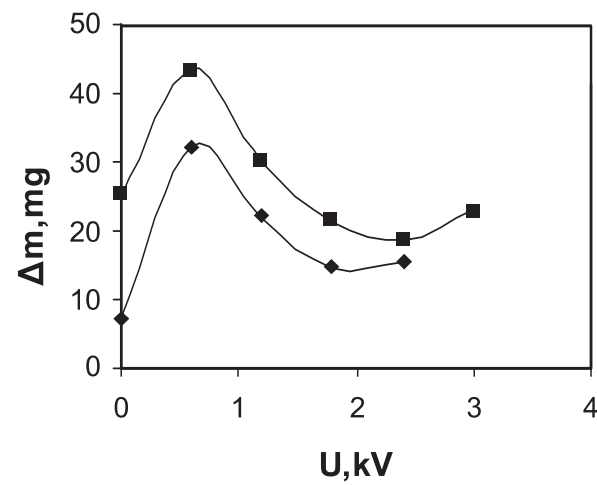

$\longrightarrow \alpha=0.8 \longrightarrow \alpha=0.64$

Figure 10. Electric field effect on carbon deposition on the electrode $\left(\mathrm{C}^{-}\right)$

The dominant field-enhanced reduction of $\mathrm{CO}_{2}$ absorption and the levels of $\mathrm{CO}_{2}$ emissions in the products, is observed in the limit of the weak fields $(\mathrm{U}<1.2 \mathrm{kV})$. The minimum value of the intensity of $\mathrm{CO}_{2}$ absorption corresponds to the maximum value of the field-enhanced carbon capture and mass growth of the deposited soot particles (Figure 10). In addition, the carbon capture reduces the absorption intensity of $\mathrm{CO}$ $\left(v=2169 \mathrm{~cm}^{-1}\right)$ and the levels of $\mathrm{CO}$ emissions in the products (Figure 12). This confirms that the carbon capture from the flame results in propane decarbonization that is partly converted into fuel with a higher hydrogen-to-carbon ratio. As shown above, the carbon capture results in a decrease of the temperature and heat loss from the flame (Figure 8). This confirms that carbon capture and sequestration from the flame decrease the

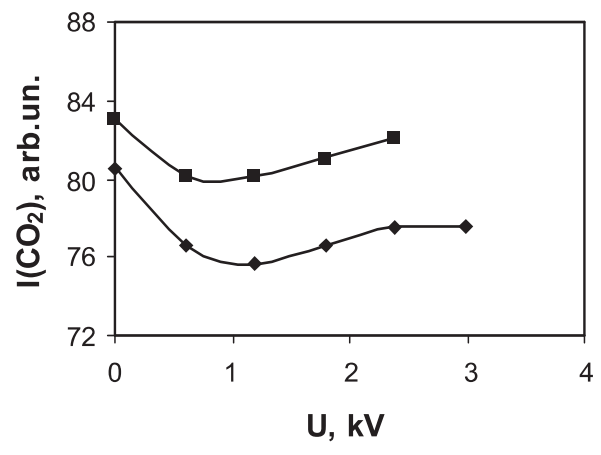

$\longrightarrow \alpha=0.625 \quad \rightarrow-\alpha=0.8$

(a)

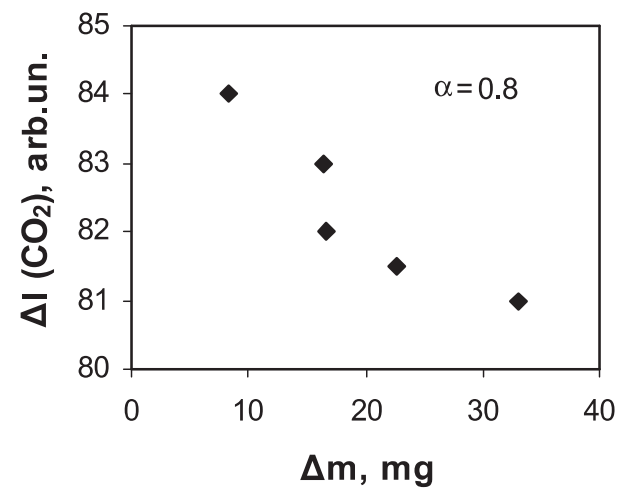

Figure 11. Correlation between the field-enhanced carbon capture and $\mathrm{CO}_{2}$ absorption intensity in the products

amount of the energy that is released during propane combustion and a part of the energy is stored in the unburned carbon.

By analogy with the field effect on the mass growth of the deposited soot particles, the field effect on $\mathrm{CO}_{2}$ and $\mathrm{CO}$ emissions reduces as the bias voltage is increased $(\mathrm{U}>1.2 \mathrm{kV})$. This correlation confirms that the dominant field effect on soot formation, carbon capture and sequestration from the flame can be obtained in the limit of weak fields. The most pronounced field effect on soot deposition, carbon capture and sequestration is observed in the range of $\alpha=0.6-1$. In fact, under fuel-rich conditions $(\alpha<0.6)$ the sheath-convection current of positive ions and the fieldenhanced mass transfer of the hydrocarbons into the flame core tends to decrease (Figure 2) by reducing the electric field effect on carbon capture

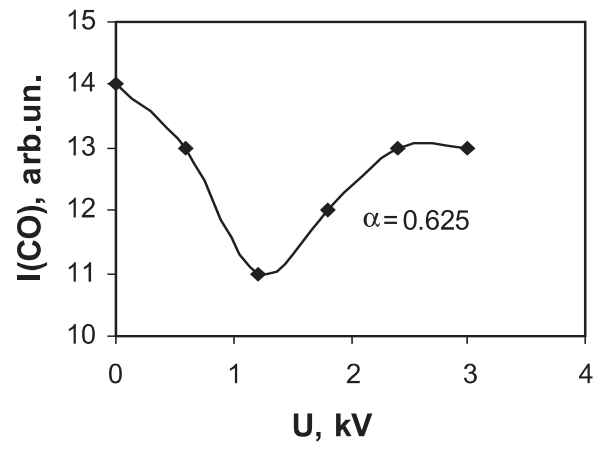

(b)

Figure 12. Electric field enhanced variations of the absorption intensity of $\mathrm{CO}_{2}$ and $\mathrm{CO}$ in the products 
and sequestration, as shown in Figures 10 and 12. It should be noted that a similar electric field effect on soot formation and deposition has been observed by Mayo and Weinberg (1970), and Weinberg (1981). These investigations demonstrate that increasing the applied potential above $1 \mathrm{kV}$ can decrease the rate of soot formation and deposition. The investigations of Mayo and Weinberg (1970) have shown that all soot particles are positively charged and the electric field removes them from the pyrolysis zone to the negatively biased central electrode determining the rate of soot deposition. The application of the electric field causes removal not only of the charged soot particles, but also of the positive molecular ions from the flame. In fact, the mobility of molecular ions significantly exceeds that of the soot particles. Therefore, if a strong field is applied to the flame, the positive molecular ions are rapidly removed to the negatively biased electrode and reduce the density of ionic soot precursors along the flame core. For such conditions the mechanism of the soot growth changes and soot particles start to grow on the uncharged nuclei. Hence, it reduces the field effect on the mass transfer of soot particles by reducing the field effect on the rate of soot deposition and carbon capture from the flame.

\section{Electric control of $\mathrm{NO}_{\mathrm{x}}$ formation}

Previous investigations have shown (Zake et al., 1998; 2000) that the electric field-enhanced heat/mass transfer from the flame core outward, and field-enhanced quenching of the reaction zone of the flame can be used to reduce the levels of $\mathrm{NO}_{\mathrm{x}}$ emissions. The present study demonstrates that field-induced local variations in the equivalence ratio produce variations in the rate of fuel combustion and heat transfer to the channel walls with corresponding variations in the temperature and levels of $\mathrm{NO}_{\mathrm{x}}$ emissions. The most pronounced field effects on $\mathrm{NO}_{x}$ emissions are obtained for fuel-lean or stoichiometric propane-air mixture $(\alpha \geq 1)$ and positively biased central electrode $\left(\mathrm{C}^{+}\right)$. Experiments for fuel-lean conditions (below the sheath breakdown) show that the field-enhanced mass transfer of the hydrocarbons, from the flame core outward, is followed by an increase in the equivalence ratio of the products and heat loss from the flame pyrolysis zone (Figures 3 and 8). The reaction

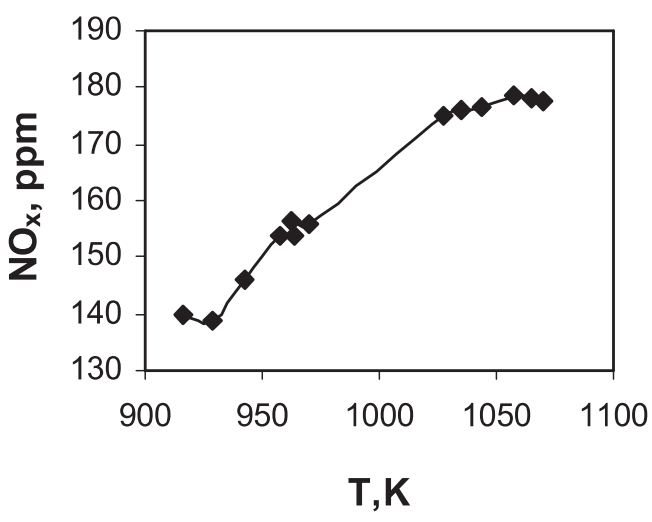

(a)

Figure 13. Temperature dependence of the levels of $\mathrm{NO}_{\mathrm{x}}$ emissions in the products $\left(\mathrm{C}^{+}\right)$

rates along the flame core are weakened, that leads to a decrease of the temperature (Figure 4) with direct influence on the levels of $\mathrm{NO}_{\mathrm{x}}$ emissions in the products. The correlation between the temperature of the products and the levels of $\mathrm{NO}_{\mathrm{x}}$ emissions from the flame channel flow is shown in Figure 13.

The reverse situation is observed for the negative bias voltage of the electrode $\left(\mathrm{C}^{-}\right)$, as the fieldenhanced mass transfer of hydrocarbons into the flame core for the fuel-lean conditions reduces the equivalence ratio of propane-air mixture and promotes a more stoichiometric propane combustion. As a result, it increases the temperature of the products (Figure 4b) with corresponding increase in the levels of $\mathrm{NO}_{\mathrm{x}}$ emissions from the flame. The voltage dependence of field-enhanced variations in the levels of $\mathrm{NO}_{\mathrm{x}}$ emissions for the positively and negatively biased central electrode is presented in Figure 14.

Note that in an analogy with the field-enhanced variations of $\mathrm{CO}_{2}$ emissions from the flame (Figure 12), the levels of $\mathrm{NO}_{\mathrm{x}}$ emissions in the products continuously decrease to a minimum value and then slightly increase as the bias voltage increases. For the strong fields $(\mathrm{U}>2 \mathrm{kV}$ and $\mathrm{E}>105 \mathrm{~V} \mathrm{~m}^{-1}$ ), a sheath breakdown occurs, and a corona discharge develops in the flame (Zake et al., 1998; 2000). In this limit, a field-enhanced destruction of the flame compounds $\left(\mathrm{C}_{2} \mathrm{H}_{2}, \mathrm{C}_{2} \mathrm{H}_{4}\right.$, $\mathrm{N}_{2}, \mathrm{O}_{2}$, etc.) is observed and local variations of the flame composition and rate of $\mathrm{NO}_{\mathrm{x}}$ formation follow then. It should be noted that a similar volt- 


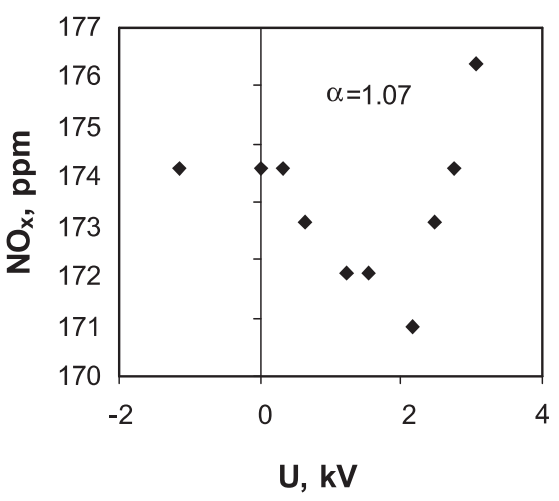

(a)

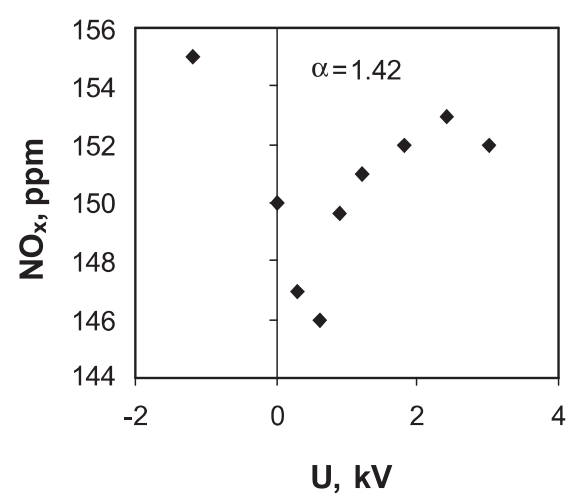

(b)

Figure 14. Electric field-enhanced variations in the levels of $\mathrm{NO}_{\mathrm{x}}$ emissions.

age dependence of $\mathrm{NO}_{\mathrm{x}}$ emissions is obtained from the results of industrial investigations, in district heating boiler houses (Zake et al., 2000). These results confirm that the field-enhanced heat/mass transfer and destruction of $\mathrm{NO}_{x}$ by corona discharge can be used as a clean-up technique to control the levels of $\mathrm{NO}_{\mathrm{x}}$ from fuel combustion.

\section{CONCLUSIONS}

Experimental studies of electric field-enhanced heat/mass transfer were performed and related variations of fuel combustion along the flame-channel flow were observed. The results of the experimental investigations demonstrate the following:

1. The local variations in the rate of reactions and the amount of heat produced by the fuel combustion are strongly influenced by the electric field-enhanced mass transfer that produces local variations of the mass fraction of the hydrocarbon radicals and the equivalence ratio along the flame channel flow.

2. The field-enhanced mass transfer of hydrocarbons into the flame core, for fuel-rich conditions and negatively biased central electrode, shows a direct influence on the processes of soot formation, and deposition on the central electrode that develop along the pyrolysis zone of the flame. Within the limit of weak fields $\left(\mathrm{U}<1.2 \mathrm{kV}, \mathrm{E}<105 \mathrm{kV} \mathrm{m} \mathrm{m}^{-1}\right.$ ), a fieldenhanced carbon capture and sequestration from the flame is obtained. The carbon capture from propane flame decreases the rate of
$\mathrm{CO}_{2}$ formation and the levels of $\mathrm{CO}_{2}$ emitted into the surrounding. Therefore, the electric field-enhanced heat/mass transfer can be used to control the carbon capture and sequestration from the flame and cleaner combustion of the hydrocarbons may be obtained.

3. The field effect on the carbon capture and sequestration from the flame decreases in the limit of strong fields (U>1.2 kV, E> $105 \mathrm{kV} \mathrm{m}^{-1}$ ). In this limit, the field-enhanced radial mass transfer of hydrocarbons into the flame core reduces the equivalence ratio of propane-air mixture and propane combustion is weakened. Therefore, the temperature along the flame core falls below the threshold temperature that confines the processes of soot growth and deposition.

4. The field-enhanced reduction in the rate of fuel combustion with related quenching of the flame core could be reached both for fuel-lean conditions and for the positively biased central electrode. In the limit of weak fields, the fieldenhanced mass transfer of the hydrocarbons causes shift of combustion the reaction zone from the flame core outwards, by reducing the temperature along the flame core and increasing the heat loss from the flame. As a consequence, the levels of $\mathrm{NO}_{\mathrm{x}}$ emissions are reduced. For strong fields (U>1.2 kV, E $>105$ $\mathrm{kV} \mathrm{m}^{-1}$ ), the field effect on the levels of $\mathrm{NO}_{\mathrm{x}}$ refers to the processes of the field-enhanced destruction of the flame compounds, by the electron impact that requires further investigation. 


\section{REFERENCES}

Brewer, P.G., Gernot, F., Peltzer, E.T. and Franklin M. Jr. (1999), Direct Experiments on the Ocean Disposal of Fossil Fuel $\mathrm{CO}_{2}$, SCIENCE, 284, 943-945.

Chomiak, J., Golovitchev, V. and Nordin, N. (1996), Modeling of Spray Formation, Ignition and Combustion in Internal Combustion Engines, Model of Soot Formation, Progress Report \#1, Chalmers University of Technology.

Faeth, G.M., Urban, D.L., Yuan., Z. and Hager, R. (1996), Laminar Soot Processes, combustion module-1, USC Nasa Lewis Research Center, University of Michigan, 1-9.

Frenklach, M. (1996), On Surface Growth Mechanism of Soot Particles, Twenty-Sixth Symposium (International) on Combustion, The Combustion Institute, Pittsburgh, PA, 2285-2293.

Glassman I. (1989), Soot formation in combustion processes, Twenty-Second Symposium (International) on Combustion, The Combustion Institute, Pittsburgh, PA, 295.

Holloway, S. (1996), The underground disposal of $\mathrm{CO}_{2}$, An Overview of the Joule II Project, Energy Conversion and Management, 37, 1149-1154.

Kaarstad, O. and Audus, H. (1997), Hydrogen and electricity from decarbonised fossil fuels, Energy Conversion and Management, 38, 431-436.

Kennedy, I.M. (1997), Models of soot formation and oxidation, Prog. Energy Combust. Sci., 23, 95-132.

Malcev, V.M., Malcev, M.I. and Kashporov, L.J. (1977), The main characteristics of combustion, Nauka Publishing, Moscow (Rus.).

Mayo, P.J. and Weinberg, F.J. (1970), On the size, charge and number-rate of formation of carbon particles in flames subjected to electric fields, In: Proceedings of the Royal Society, A 319, 351-371.

Place, E.R. and Weinberg F.J. (1965), Electrical control of flame carbon, In: Proceedings of the Royal Society, A 289, 192-205.

Smy, P.R. (1976), The use of Langmuir probes in the study of high-pressure plasmas, Advances in Physics, 25, 517553.

Socolow, R. (1997), Fuels decarbonization and carbon sequestration, Technological Opportunities for Fuels Decarbonization and Carbon Sequestration, Center for Energy and Environmental Studies, School of Engineering and Applied Science, Princeton University, PU/CEES Report No. 302.

Weinberg, F.J. (1981), Electrical intervention in the sooting of flames, Soot in Combustion Systems and its Toxic Properties, N.A.T.O. and University of Alsace, 1-14.

Zake, M. and Purmals, M. (1999), The electric field-controlled heat and mass transfer and fuel combustion in the flame channel flows, Magnetohydrodynamics, 35, 131-142.

Zake, M., Purmals, M. and Lubane, M. (1998), Enhanced electric field effect on a flame, Journal of Enhanced Heat Transfer, 5, 139-163.

Zake, M., Turlajs, D. and Purmals, M. (2000), Electric field control of $\mathrm{NO}_{\mathrm{x}}$ formation in the flame channel flows, GLOBAL NEST: the International Journal, 2, 99-109. 